\title{
DISCUSSION OF THE SIX PRECEDING ARTICLES
}

The President, Dr. R. M. Warren, thanked the speakers for their very full and comprehensive treatment of an important subject. The material presented had been controversial in some respects and he called on Dr. Dudley Hart to open the discussion.

Dr. F. Dudley Hart (Westminster Hospital, London) said he was honoured to be present at a meeting of the Society; he was interested to hear so much excellent material presented and he would go back to his cases of spondylitis to find how many had Reiter's disease. He was interested in the point about new lesions made by Dr. Csonka.

He thought there were clear differences between the two groups of patients and that they should be kept separate for the present until further knowledge came to light. He was against the American idea of including cases of spondylitis in series of cases of rheumatoid arthritis, although Dr. Walter Bauer thought that these conditions could be studied better if considered together.

Dr. R. M. Mason (London Hospital) said that it had been recorded that 10 per cent. of cases of ankylosing spondylitis had peptic ulcers, but he thought this was an underestimate. Dealing with the question of deep $x$-ray therapy, he had found Butazolidin to be the most effective treatment. He reserved the use of deep $x$ rays for difficult cases in which the inherent risk was worth taking, although the benefit produced might not be immediately apparent and controlled studies had not been possible.

He was delighted to hear Dr. Grainger's very clear account and was most impressed by his $x$ rays. He felt though that sclerosis came early in some cases. He had found the meeting most stimulating and it had suggested several further possible lines of research.

Mr. A. J. King (Whitechapel Clinic) said that he was impressed by all the material that had been placed before the Society. The subject had been dealt with very fully and the material presented had been excellent. Many questions had been raised to which he did not know the answers.

Dr. Grainger had used the term prostato-vesiculitis. He felt that this was a better term than prostatitis because the seminal vesicles were so often involved in addition to the prostate. Dr. Mason had asked whether chronic prostatitis should be treated. Some symptoms due to chronic prostatitis could be relieved by treatment in some cases. His own opinion was that prostatitis was not curable, and the question whether treating chronic prostatitis in cases of spondylitis would do any good could only be settled by a proper investigation with controls. The important question of the cause of so-called non-specific genital infection had been raised. There was much investigative work to be done and not enough was being undertaken. He thought the place of pleuropneumonia-like organisms in this matter had not been settled. Dr. Dudley Hart had suggested that these various syndromes should be kept apart, but he felt that it was possible that the subject had suffered from too rigid a separation into categories in the past. Nevertheless, until more was known the separate categories should perhaps be kept, bearing in mind that they might represent different reactions of the patients to the same disease.

Dr. Allan Grimble (Guy's Hospital, London) thanked the speakers for their excellent papers. He had found that somewhere near a half of a small series of patients with venereal arthritis (Reiter's disease) had complementfixing antibodies to P.P.L.O. In the mechanism of the arthritis he was interested in the Batson venous drainage system, but he considered there were other possible mechanisms such as those involved in the generalized response to localized foci, as occurred in scarlet fever.

Dr. G. L. M. McElligott (St. Mary's Hospital, London) thanked the speakers for giving the Society a most enjoyable evening. There were two points he wished to raise. First, Dr. Mason's statement that the body reaction to different stimuli might be the same. This could be explained by the fact that the sacro-iliac synchondrosis would be the first place to be reached by the pelvic lymphatics. The second point was that a very large number of the cases of Reiter's syndrome presenting at St. Mary's had had bacterial urethritis in the past. In a number this had been due to the gonococcus. Should this condition not be called "Infective Arthritis"? Dr. Csonka had found that no less than 76 per cent. of cases of Reiter's syndrome had a past history of gonorrhoea and this was surely more than mere coincidence?

Dr. W. Fowler (Wolverhampton) pointed out that the material analysed by Romanus was different from that seen in Great Britain. As an example, it was mentioned that chronic cowperitis was diagnosed on clinical grounds in 39 ( 40 per cent.) of 95 cases studied by Romanus, whereas in his experience chronic cowperitis was exceptionally rare in Great Britain, at least in V.D. Clinics. He had examined a series of 47 male cases of ankylosing spondylitis and had been unable to discover any convincing evidence to support Romanus' hypothesis. 
He did not think it right to argue post hoc propter hoc in regard to the so-called "venereal" arthritis. It would be a different matter if a number of patients could be found who had developed Reiter's syndrome after coitus with the same consort. It might well be that the urethritis was part of the syndrome and not its cause, as was certainly the case in post-dysenteric Reiter's disease. The term "venereal" should not be applied to arthritis associated with non-specific urethritis until very strong circumstantial evidence to support the hypothesis was produced, or a specific organism was recovered.

Dr. J. K. Oates (Whitechapel Clinic) stated that it was a remarkable and unexplained fact that less than 10 per cent. of cases of Reiter's disease occurred in women.

Dr. G. W. Csonka (St. Mary's Hospital, London) stated that, with regard to the point raised by Dr. Fowler, he had two male patients who had developed Reiter's syndrome after coitus with the same female consort.

Dr. R. R. Willcox (St. Mary's Hospital, London) said that, with regard to the epidemiological point raised by Dr. Fowler, he believed that Dr. Siboulet of Paris had a small series of cases in which more than one contact of a particular source of infection had developed Reiter's disease.

Dr. Ronald Grainger (St. Thomas' Hospital, London) felt that, in most cases, evidence of articular cortical destruction on the iliac side of the joint space was the earliest radiological sign of sacro-iliac arthritis. It might be particularly difficult in women to differentiate the later sclerotic changes of spondylitic sacro-iliitis from osteitis condensans ilii.

There was no real evidence that the sacro-iliac arthritis of ankylosing spondylitis was an infective arthritis in the sense that organisms might be present in the joint, and he had not meant to suggest that. What he had meant to suggest was that infection of the pelvic viscera might, in a manner as yet unknown, provoke the onset of bilateral, destructive, non-suppurative sacro-iliac arthritis. Perhaps the vertebral venous system was the route through which this effect might be mediated.

Mr. A. J. King referred to the point raised by Dr. Fowler. He was astonished that anyone working in the subject could have doubts that non-specific urethritis was a venereal disease. 